\title{
The use of technology in informal English language learning: evidence from Yemeni undergraduate students
}

\author{
Wagdi Rashad Ali Bin-Hady \\ Department of English, Hadhramout University, Mukalla, Yemen, and \\ Nasser Omer Mubarak Al-Tamimi \\ Department of English, Seiyun University, Sieyun, Yemen
}

Informal English language learning

\begin{abstract}
Purpose - This study aims to explore the use of technology-based strategies by Yemeni undergraduate students to develop their English as a foreign language skills in informal learning settings.

Design/methodology/approach - A mixed methods research design was used to collect quantitative and qualitative data from 110 undergraduate students enrolled at the English Departments in two universities in Yemen. In the first phase of the study, 10 students were interviewed to obtain information about their use of technology to develop their English language skills and subsystems in informal settings. Following the analysis of the interview data, a questionnaire was built to collect quantitative data, and the second phase of the study was carried out with 100 undergraduate students.

Findings - The findings revealed that students developed four technology-based strategies that they used in informal settings. These strategies included using social media, being inspired by someone, accessing social networks and websites. Students reported that these strategies helped them develop their listening, speaking and reading skills, while they also reported that their vocabulary was enhanced over grammar and pronunciation.

Research limitations/implications - The study findings can be of benefit not only for helping to raise students' awareness of informal learning strategies to develop their English skills outside the classroom but also for teachers to rethink the importance of integrating technology tools and digital resources in their teaching practice. The results could also guide curriculum designers to augment textbook materials by integrating technology-based informal learning strategies.

Originality/value - This is the first study on this topic conducted in the context of higher education in Yemen and offers unique insights into informal learning practices of Yemeni students. In addition, the findings of the study open new dimensions for rethinking the classification of language learning strategies to include those that are technology-based and mainly useful for independent informal learning.
\end{abstract}

Keywords EFL learners, Informal English language learning, Technology-based strategies, Language skills, Language subsystems

Paper type Research paper

(C) Wagdi Rashad Ali Bin-Hady and Nasser Omer Mubarak Al-Tamimi. Published in Learning and Teaching in Higher Education: Gulf Perspectives. Published by Emerald Publishing Limited. This article is published under the Creative Commons Attribution (CC BY 4.0) licence. Anyone may reproduce, distribute, translate and create derivative works of this article (for both commercial and non-commercial purposes), subject to full attribution to the original publication and authors. The full terms of this licence may be seen at http://creativecommons.org/licences/by/4.0/legalcode

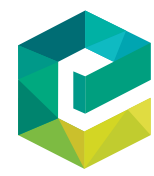

Learning and Teaching in Highe Education: Gulf Perspectives Vol. 17 No. 2, 2021 Emerald Publishing Limited Emerald Publishing Limited DOI 10.1108/LTHE-09-2020-0037 


\section{LTHE}

17,2

\section{Introduction}

The use of technology and the Web has had a tremendous impact on the second language (L2) classroom with students no longer depending on their teachers and their textbooks as the main source of exposure to L2 (Trinder, 2017). However, technology on its own is not going to do much to help L2 students improve their language skills. Students need to use learning strategies to improve their language skills however challenging this might be (Hockly, 2013). While there is a plethora of studies that have focused on technology use in the L2 classroom in the Middle East (Alassaf, 2014; Ali, 2017; Bin-Hady, Al-Kadi, Alzubi, \& Mahdi, 2020; Kareem, 2017), there is a dearth of research studies in the tertiary context of Yemen. Similarly, some studies have focused on online informal L2 learning (Jurkovič, 2019; Isbell, 2018; Sockett, 2013), but there are no such studies done in Yemen. Yemen has been in a state of war for the past seven years with a deteriorating economy and little government concern for the use of technology in higher education. There is a need for a study that explores the use of technology in a challenging learning context like Yemen, where the internet is still very slow and not accessible to everybody (Bin-Hady et al., 2020).

The educational system in Yemen follows traditional teaching approaches. Students in public schools start to learn English as a foreign language (EFL) in the seventh grade. By the time they graduate from secondary school, they have completed six years of EFL study using localised textbooks like the Crescent English Course for Yemen. Lessons are delivered using a traditional teacher-centred approach even though according to O'Neil and Snow (2011) the textbooks were based on the communicative approach to EFL. This kind of EFL teaching continues in higher education.

Over the past seven years, universities in Yemen have experienced a brain drain because of the war. The majority of university professors migrated to the neighbouring Gulf countries searching for better living conditions and escaping from the war. This has contributed further to the deteriorating state of higher education learning in Yemen. Despite these hard and challenging conditions, Yemeni students try to do their best to improve their L2 language skills by any means available to them. It is important to document these efforts and this motivated the present study which aimed to investigate L2 learners' utilization of technology-based strategies to develop their English language competence in informal learning settings.

\section{Literature review}

Acquiring any language requires sufficient competence in the four language skills (listening, speaking, reading and writing) and related subsystems (vocabulary, grammar, pronunciation). Zhou and Wei (2018) conducted a meta-analysis of 60 research studies in the field of language learning with technology. They explained how both teachers and learners used technologies in learning language skills and subsystems and how such learning with technology can enhance learners' self-regulated learning. Moreover, Trinder (2017) studied Canadian students' use of various technologies to develop their language competencies (language skills and subsystems). Trinder's study reported that students preferred to use online resources and media (films, online dictionaries) in their self-regulated time than using such resources in the classroom.

In the Middle East region, Ali and Bin-Hady (2019) investigated the use of WhatsApp in developing EFL Saudi learners' language skills and subsystems. The study, which surveyed 55 students, found that WhatsApp has a high positive impact on the learners' English language acquisition. Furthermore, Kareem (2017) studied the pros and cons of technology in the Kurdish context from both students' and teachers' perspectives. The study revealed that technology plays a positive role in developing students' speaking 
proficiency. In Jordan, Alassaf (2014) studied the use of technology in higher education. The study interviewed 44 lecturers at 16 Jordanian Universities and showed instructors' positive attitudes toward the implementation of technology in the teaching and learning environment. The study also revealed some of the factors that restricted the successful integration of technology in the teaching and learning process such as weak infrastructure, limited financial resources and the lack of teacher training. In Saudi Arabia, Ali (2017) investigated the impact of using Blackboard on EFL students' motivation. The study which recruited $80 \mathrm{EFL}$ students at Bisha University found that Blackboard motivated EFL students' learning more than learning via traditional methods. While the use and impact of technology in formal educational contexts has been researched, its use in informal learning settings is still in its infancy.

\section{Informal learning}

Informal learning is considered "self-directed [. . . ] rather than curriculum-based" (Lai et al., 2013, p. 415). It generally refers to self-study that usually occurs outside the classroom. Trinder (2017) states that "informal learning is learner-controlled, not linked to any course or institution, and takes place outside the classroom" (p. 402). According to Sefton-Green (2004), informal learning is any learning that occurs outside the school context and the purpose of learning. That is to say, informal learning is meant for pleasure, it is not structured and it happens "unconsciously, unintentionally, incidentally, naturally, anywhere at any time without any method, by various means, alone or in cooperation with others" (Gramegna, 2012, p. 2). Similarly, Stevens (2009) mentions that "informal learning may be intentional but in most cases it is non-intentional (or "incidental'/random)" (p. 12). However, this view has been questioned by Trinder (2017) who reported that through technology and online resources learners are also exposed to EFL learning materials, and this can lead to purposeful rather than incidental informal learning. Furthermore, Eraut (2004) asserted that this type of learning focuses on individualism than socialization. It is parallel to learning from experience and can be mooted as implicit, reactive and deliberative learning. Finally, Isbell (2018) reports that informal language learning provides L2 learners with opportunities for using the language in real communication.

With the advent of Mobile-Assisted Language Learning (MALL) and access to smart mobile phones, EFL students have been able to increase their exposure to English and improve their English language skills anytime, anyplace and without restrictions. For example, Jurkovic (2019) explored the use of smartphones in informal EFL learning by undergraduate students in Slovenia. The study revealed that students used online resources to develop their competence in English. However, even in informal learning settings, EFL students need more than just motivation and opportunity for learning. They need to adopt strategies to successfully advance their learning beyond the walls of the formal classrooms (Mahajaroenkul, 2017; Zhou and Wei, 2018).

\section{Informal learning strategies and technology}

Learning strategies "support learning by actively engaging a person's mental process" (Irawati, 2015, p. 81). Such learning strategies can be developed by the language learners themselves according to the learning setting (Kukulska-Hulme, 2012; Nguyen and Terry, 2017). Some strategies are used in the classroom, whereas others are more suitable for use outside of the classroom. Such informal learning strategies are the core aim of the present study.

Applied linguistics research has identified a number of different language learning strategies (LLSs). For instance, Oxford (1990) classified LLSs into direct and indirect 
LTHE

17,2

strategies. The former includes memory, cognitive and compensation strategies, whereas the later comprises metacognitive, affective and social strategies. However, the relationship between learning strategies and technology needs to be explored (Pawlak and Oxford, 2018). Learners may adapt different learning strategies when using technology from the above mentioned direct and indirect strategies. Pawlak and Oxford (2018) stated:

Given the nature of interaction [of learning strategies] with new technologies, there are grounds to assume that patterns of strategy use in these situations might be considerably different from those in the classroom or in learners' own time when they practice the TL in more traditional ways (e.g., greater focus on social strategies can perhaps be expected) (p. 530).

The use of technology in English language teaching (ELT) is of great importance these days. Vazquez and Lario-de-Oñate (2009) advocated that the use of technology can enhance students' cognitive skills through the use of language learning strategies (LLSs). Moreover, Valentín et al. (2013) studied the relationship between technology, motivation, learning strategies and academic performance. They found that university students used technology in four different ways: social use in synchronous or asynchronous communication and reading; technical use activated in data "professional tools" such as "databases, web page design, etc."; academic use which represents the use of applications like "word processors, slide presentation software, etc."; and, educational platforms which comprised both "learning software platforms and e-mail" which offer virtual learning to students (pp. 8-9). More recently, Pereira et al. (2019) explored the informal learning strategies used by Portuguese teenage learners in informal settings using media. The study found that learners used three learning strategies: trial and error; imitating or being inspired by someone; and searching for information. Moreover, Mahajaroenkul (2017) examined whether international students used social media in their informal EFL learning before traveling to the USA. The study revealed that students used the informal learning strategy of accessing social media like watching movies and other audiovisual resources. In the Arab educational contexts, Bin-Hady et al. (2020) explored the use of LLSs with technology in two settings, Yemen and Saudi Arabia. The study found that Saudi EFL learners used LLSs more than the Yemenis. The study reported that such variation in LLSs was due to the wider availability of technology in Saudi Arabia and its limited availability in Yemen.

In the present study, technology-based strategies refer to the tools and techniques which a learner deploys outside of traditional formal learning settings, such as schools and colleges, to develop one's competence in EFL. In particular, the study aimed to explore the following research questions:

$R Q 1$. What language skills do Yemeni EFL students focus on during their use of technology in informal learning settings?

RQ2. What language subsystems do Yemeni EFL students focus on during their use of technology in informal learning settings?

RQ3. How often do Yemeni EFL learners use technology-based strategies in informal learning settings to optimize their English learning?

\section{Methodology}

Research design

The study used an exploratory sequential mixed methods design by "first gathering qualitative data to explore a phenomenon, and then collecting quantitative data to explain relationships found in the qualitative data" (Creswell, 2012, p. 543). In the first phase of the 
study, 10 students were interviewed to obtain information about their use of technology to develop their English language skills and subsystems in informal settings. Following the analysis of the interview data, a questionnaire was built to collect quantitative data, and the second phase of the study was carried out with 100 undergraduate students.

\section{Participants}

This study included 110 undergraduate students in Yemen. A total of 10 students participated in the interview, and 100 students responded to the subsequent questionnaire. All participants were Yemeni nationals and they were in the first, second, third and fourth levels of an EFL program in two Universities (A and B) in Yemen. Students were enrolled in two colleges in each university. The sample comprised 55 males and 55 females, 60 from University A and 50 from University B, aged between 19 and 23. Participants had studied English for six years before enrolling in their college, and they differed in terms of their English language proficiency (from pre-intermediate for the first and second level students to intermediate for students in levels three and four). Participants came from semi-urban cities such as Seiyun and Al-Mahra and a rural city like the island of Socotra. Students had access to limited types of technology like mobile phones and TV. They were able to watch news and movies. Internet access allowed them to chat with others using WhatsApp or Imo. Moreover, students could share PDF files, videos and audio via Share It.

Two sampling techniques were used in this study: purposeful sampling for recruiting the 10 students who voluntarily agreed to be interviewed ( 5 students from each university); and random sampling for the 100 students who responded to the questionnaire. Purposeful sampling according to Griffee (2012), should be "knowledgeable and available persons" (p. 58). The students selected for the interviews had knowledge about technology and they actually used technology in their learning. Their responses were the basis for the creation of the questionnaire. The ten students who responded to the interview questions were excluded from responding to the questionnaire.

\section{Data collection instruments}

Driven by the nature of the research problem, two instruments were used to collect data from the participants: an interview and a questionnaire. The interview was used to collect data from ten students (Phase 1). Students were interviewed individually in English and their responses were recorded using a mobile phone. Where necessary, Arabic was used for clarification.

Subsequently, a questionnaire was prepared in light of the participants' responses to the interview (Phase 2). The questionnaire collected frequency data related to the following variables: informal learning, technology-based learning strategies, language skills (listening, speaking, reading and writing) and language subsystems (grammar, pronunciation and vocabulary). For the items included in the questionnaire, see Appendix.

Prior to the data collection, the instruments were piloted to check their validity and reliability. Two ways were used to ascertain the validity of the questionnaire and the interview questions: self-validation and expert validation. In the former, the researchers asked themselves whether each developed item in the instruments measured what it was supposed to measure. In the latter, the researchers gave the instruments to three experts with Doctorate degrees in the field of Applied Linguistics and technology to check every item against the objectives of the study. With regard to the reliability of the questionnaire, Cronbach's alpha was calculated. The result indicated a high reliability of 0.86 . 


\section{LTHE}

17,2

\section{2}

\section{Table 1.}

Themes and frequencies obtained from interview data on the development of the four language skills

\section{Data analysis}

After the interviews were transcribed, they were thematically analysed. Then, a coding system was used: SSN where SS stands for student and N stands for number of student. The data were categorised into eight themes and each theme was coded into subcategory(ies). Then percentages were calculated for each of the subthemes (Tables 1 and 2).

The questionnaire items were coded using numerical values. A five-point frequency scale was used (from 5 - Always to 1 - Never). The quantitative data were descriptively analysed according to the four categories of technology-based strategies (Figure 1) using SPSS. Mean scores and standards deviations were calculated.

\begin{tabular}{llc}
\hline Themes & Codes & Frequency \\
\hline Developing listening skills & Watching movies & 6 \\
& Listening to news and audios & 4 \\
Developing speaking skills & Talking with native speakers & 6 \\
& Talking with non-native speakers & 3 \\
& No focus on speaking & 1 \\
Developing reading skills & Reading eBooks & 10 \\
Developing writing skills & Chatting with people & 5 \\
& Writing what is going in my head & 2 \\
& No focus on writing & 3 \\
\hline
\end{tabular}

\section{Table 2.}

Themes and frequencies obtained from the interview data on the development of language subsystems

\begin{tabular}{llc}
\hline Themes & Codes & Frequency \\
\hline Developing English grammar & Reading eBooks on grammar & 4 \\
& Watching grammar videos & 4 \\
& No focus on grammar & 2 \\
Developing English vocabulary & Reading eBooks and magazines & 6 \\
& Using mobile dictionary to get the meaning & 4 \\
Developing English pronunciation & Talking with/listening to native speakers & 5 \\
& Using mobile dictionary to check the pronunciation & 2 \\
& No focus on pronunciation & 3 \\
\hline
\end{tabular}

Figure 1.

Classification of EFL students' use of technology-based learning strategies in informal learning settings

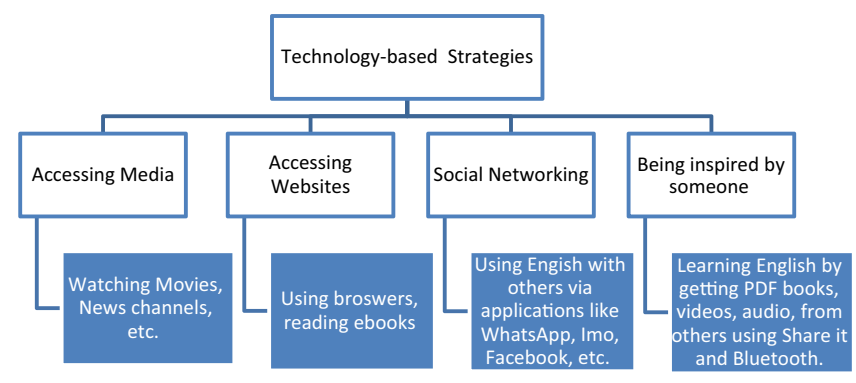




\section{Results}

The findings of the study are presented below in order of the three research questions. In each research question results based on data from the relevant instrument(s) (interviews and/or questionnaires) are presented.

RQ1: What language skills do Yemeni EFL students focus on during their use of technology in informal learning settings?

To answer the first research question, students' responses to the interview regarding how they develop their English language skills with technology tools were coded and analysed (Table 1). In terms of listening, 6 out of 10 students reported that they developed their listening skills by watching movies, whereas another four students reported listening to news and audio materials. The following excerpts from the interviews exemplify some of the students' answers:

I listen to the native speakers and train my ears about the different accents like American or British (SS1).

I use my mobile and TV ICT tools. I always watch movies and programs in channels like MBC2 $\mathrm{MBC}$ Action, $\mathrm{BBC}$ to get news about the world, weather and everything in English. So, I can I improve my listening skills (SS7).

Students were also asked about how they develop their speaking skills. A total of 6 out of 10 students were reported talking with English native speakers, whereas 3 students were reported talking with non-native speakers. Only one student replied that they did not use technology to develop their speaking. The following interview excerpts provide examples of the students' answers:

I speak with native speakers on WhatsApp because I am a member in some groups. I speak with the members sometimes in private and other times in public. We speak about topics that the admin suggests (SS4).

I use the internet by connecting with native speakers using WhatsApp (SS9).

I cannot use any ICT tool to improve my speaking; to improve my speaking skills (SS2).

All of the students said that they develop their reading by downloading and sharing eBooks on their mobiles:

I use Google to read a lot about any topics and PDF. I usually use WhatsApp Application (SS4).

I use my phone to read PDF books by sharing them from friends. If I have internet access I read online books (SS1).

I download some PDF books and like short stories and read them using my phone. But, I use the library a lot of time to develop my reading skills (SS8).

Finally, half of the interviewees said that they develop their writing by chatting with people, whereas two students reported writing what goes on into their heads and another three said that they did not use technology tools to develop their writing skills:

I use the internet to download books about writing (SS3). 

how write sentences, how to correct the mistakes in any sentences and even how to write a paragraph about yourself (SS6).

Only I have a program which supports me with the correct spelling when I chat with somebody. I don't use many programs to improve my writings (SS9).

To conclude, students reported that they used technology tools to develop their English listening, speaking and reading skills, while writing was the least developed skill with students reporting that they use technology tools to practise informal rather than academic writing. The data from the interviews in terms of the four language skills are summarised below in Table 1 .

\section{RQ2: What language subsystems do Yemeni EFL students focus on during their use of} technology in informal learning settings?

In answering the second research question, themes and codes obtained from the students' responses to the interview were analysed. Four of them said that they read eBooks on grammar via their mobile phones. Another four students reported that they watch videos about grammar, while two students replied that they did not use technology tools to develop their grammar. The following excerpts from the interviews exemplify the students' answers:

When I watch movies, I learn how to use grammar tenses and when to use them (SS10).

When I get any difficulty in the grammar course on college, I use my mobile to get some information (SS5).

I don't focus too much grammar (SS2).

The L2 subsystem investigated in this study was vocabulary. Six out of the ten students reported that they read eBooks to develop their vocabulary on their mobiles while another four students said that they use mobile dictionaries (e.g. Longman or Oxford) to find the meaning of new vocabulary. Here are some of their responses:

I use Oxford/Longman Mobile dictionary to look up any word because you can find it easily by just typing the letters. I also learn the word by typing it (SS1).

I got the meaning and many examples about the use of the words (SS5).

Finally, half of the students said that they develop their pronunciation by talking with or listening to native speakers of English, whereas two students reported using their mobile dictionaries to check the pronunciation of new words. Finally, two students reported that they did not focus on technology tools to develop their pronunciation because of how difficult it is to practise this skill. Examples of the students' answers are provided below:

I listen to native speaker during my talk. I also listen to some programs and channels like MBC channel. I use my mobile Oxford and Longman dictionaries to get the pronunciation when I got any problems in the pronunciation (SS1).

I have a program called pronunciation, but I don't know how to use it (SS5).

In fact, I don't focus about the pronunciation. It is a difficult subject (SS4). 
To conclude, students reported that they use technology to develop their grammar, vocabulary and, to some extent, their pronunciation. The results are summarised in Table 2.

\section{RQ3: How often do Yemeni EFL learners use technology-based strategies in informal learning settings to optimize their English learning?}

Students' responses during the interviews were organised in terms of the use of technologybased strategies to boost their competence in the four language skills and subsystems in informal learning settings. Moreover, their responses were classified into four broad categories (Figure 1), and each category included examples of applications and tools reported by the students. These four categories were then developed into a questionnaire which aimed to examine students' frequency of use of each category of strategies (Appendix).

The students' responses to the questionnaire were analysed in terms of overall technology-based strategies, i.e. social networking, accessing media and websites and being inspired by someone. As Table 3 shows, the overall mean score of the technology-based strategies was 2.9 out of 5 with a standard deviation of 0.550 , indicating a medium overall use of technology-based strategies, based on established strategy usage criteria by Oxford and Burry-Stock (1995) in which a mean of 3.5 or higher is considered high, a mean of 2.5 3.4 is considered medium and a mean of 2.4 or lower is considered low. These criteria were used as a benchmark to classify the usage of the different technology-based strategies by Yemeni university students to develop their skills in English.

The average frequency of use of each of the four categories of technology-based strategies was also calculated. Accessing media was found to have the highest level of usage and media tools included TV, movies and news channels accessible in every household, even in developing countries such as Yemen. Results also showed a medium level of use for the social networking strategies. Social networking included the use of apps such as WhatsApp, Imo, Facebook, Instagram, etc. These tools were used for social connections with others. Furthermore, students reported being inspired by others such as getting some help from a Facebook group administrator or getting a PDF, eBooks, videos or audios from friends using sharing applications like Bluetooth, SHAREit, etc. Such materials were used informally for the improvement of the students' English language competence and they showed a medium level of usage. Finally, accessing websites had the lowest level of usage among the four strategies and it included using browsers and applications to search for information needed for English language learning.

\section{Discussion}

Based on the interview and questionnaire results, the study found that Yemeni undergraduate EFL students use four main technology-based strategies: social networking, accessing media and websites and being inspired by someone to improve their English language in informal settings. The results of this study matched to some extent the findings

\begin{tabular}{lccl}
\hline Strategy category & Mean & SD & Range of Use \\
\hline Social networking & 2.8 & 0.572 & Medium \\
Accessing media & 4.5 & 0.931 & High \\
Accessing websites & 1.7 & 0.464 & Low \\
Being Inspired by Someone & 3.0 & 0.796 & Medium \\
Overall use of technology-based strategies & 2.9 & 0.550 & Medium
\end{tabular}

Informal English language learning

\section{$-2$}


LTHE

17,2

of Pereira et al. (2019) who found that adult students used trial and error, imitating or being inspired by someone and searching for information. Based on the mean scores for each of the strategies explored in this study, strategies for accessing media were the most frequently used. This finding echoes Trinder's (2017) study who found that students preferred to use media in self-regulated time than using such technology strategies in classroom. In contrast, accessing website strategies were used the least probably because websites require sufficient internet speed to be used and Yemen, like many developing countries, is not able to provide high speed Internet connection to its people.

Social networking and being inspired by someone showed a medium level of use. The study also revealed that only male students used such strategies, primarily because female students in Yemen may not talk with males on social media, and some students may not be allowed to own a mobile because of their conservative customs. In a previous study, BinHady et al. (2020) found that Yemeni EFL learners use LLSs in technology environments less than their Saudi counterparts. They justified such finding by the lack of technology infrastructure in the Yemeni learning context as opposed to the rich availability of such technologies in the Saudi context. Moreover another justification for the relatively low use of social networking strategies is the students' low level of competence in using such tools.

Regarding the four language skills, reading, listening and speaking were the most reported skills to be enhanced with technology tools outside of the EFL classroom, whereas writing was the least developed skill with such tools. Students can get audio or videos to practise listening comprehension at home. Similarly, they can get eBooks and read them using their mobiles during their free time. Students can also practise speaking using various applications such as WhatsApp, Imo, etc. to speak with their friends, or practise English with native speakers on a WhatsApp group, as one of the students reported. However, the study showed that writing is difficult to practise in the same way and whenever students practise writing; this is limited to informal chatting, rather than more academic forms of writing. These findings are similar to the findings by Nordin, Salehi, and Embi (2013) who reported that students used technology in classroom to develop their writing, however, they wrote short forms, not formal writing. In terms of the language subsystems, all students reported that they use technology to enhance their grammar and vocabulary, while only two-thirds of them reported using technology to improve their pronunciation skills. A third of the students said they did not focus on pronunciation because of its complexity. To summarize, all the three language areas were enhanced through technology-based informal learning, and these findings are in line with Drigas and Charami's (2014) study who found that technology enhanced their students' vocabulary, reading and speaking.

\section{Conclusion}

The current study is an attempt to explore and categorize the technology-based strategies that Yemeni undergraduate students use outside the classroom to develop their English language. The study found that students generally adopted four technology-based strategies in informal learning: accessing media such as watching movies to develop their repertoire of skills in listening, speaking or culture; being inspired by someone was the second most frequently used strategy by students who are more competent in English and the use of technology. Such inspiration stemmed from students' interactions with WhatsApp group members. Similarly, students reported that they use social networking to develop their language skills. For example, in order to know more about English people's culture, they read novels or short stories online. The strategy used the least by students was accessing websites to search for information. Regarding the language skills and 
subsystems, students integrated different strategies to develop their reading, speaking and listening skills, whereas writing was found to be less used.

The study findings can be of benefit not only for helping to raise students' awareness of informal learning strategies to develop their English skills outside the classroom but also for teachers to rethink the importance of integrating technology tools and digital resources in their teaching practice. The results could also guide curriculum designers to augment textbook materials by integrating technology-based informal learning strategies. Moreover, the findings of the study open new dimensions for rethinking the classification of LLSs to include those that are technology-based and mainly useful for independent informal learning.

Some limitations have surfaced while conducting this study and have to be acknowledged. At the foremost, the study is limited to self-report data, while an empirical method of investigation would provide an in-depth exploration. Furthermore, as the topic of informal language intake is difficult to gauge and identify, it is challenging to decide which aspect of the language has been developed due to technology tools and strategies. A comparative study of the use of learning strategies in formal and informal settings would be useful for checking the validity of the use of informal learning strategies as revealed by this study. Finally, similar studies need to be conducted in other contexts to check the validity of the taxonomy of technology-based strategies formulated in this study (Figure 1).

Despite its limitations, the present study unveiled technology-based strategies used outside the classroom by undergraduate EFL students in Yemen to boost their English proficiency and to compensate the limited face-to-face interactions they have with native and fluent speakers of English. It is hoped that the study has made a contribution, albeit small, in providing an insight into the learning efforts of EFL students in a war-ravaged country and how technology is making a difference in their L2 acquisition despite challenges in its accessibility and affordability.

\section{References}

Alassaf, H. A. (2014). Effective strategies on using ICT for teaching and learning undergraduate level at Jordanian universities. Journal of Education and Practice, 5(3), 81-89.

Ali, J. K. M. (2017). Blackboard as a motivator for Saudi EFL students: A psycholinguistic study. International Journal of English Linguistics, 7(5), 144-151.

Ali, J. K. M. \& Bin-Hady, W. R. A. (2019). A study of EFL students' attitudes, motivation and anxiety towards WhatsApp as a language learning tool. Arab World English Journal, Special Issue on call, (5), 289-298.

Bin-Hady, W. R., Al-Kadi, A., Alzubi, A. A., \& Mahdi, H. S. (2020). Assessment of language learning strategies in ICT-based environment. In S. M. Yilan \& K. Koruyan, (Eds.), ICT-Based assessment, methods, and programs in tertiary education. IGI Global. 83-99. doi:10.4018/978-17998-3062-7.ch005.

Creswell, J. W. (2012). Educational research: Planning, conducting, and evaluating quantitative and qualitative research (4th ed.). Pearson Education.

Drigas, A. \& Charami, F. (2014). ICTs in English learning and teaching. International Journal of Recent Contributions from Engineering, Science \& IT, 2(4).

Eraut, M. (2004). Informal learning in the workplace informal learning in the workplace. Studies in Continuing Education, 26(2), 247-273. doi: 10.1080/158037042000225245.

Gramegna, B. (2012). Formal language teaching versus informal language learning supported by mobile devices. ICT for Language Learning. PIXEL.

Griffee, D. T. (2012). An introduction to second language research methods: Design and data (1st ed.). TESL-EJ Publications. 

Teaching Journal, 1(1), 81-87. doi: 10.1007/s13398-014-0173-7.2.

Isbell, D. R. (2018). Online informal language learning: Insights from a Korean learning community. Language Learning and Technology, 22(3), 82-102.

Jurkovič, V. (2019). Online informal learning of English through smartphones in Slovenia. System, 80, $27-37$.

Kareem, N. N. (2017). The importance of using information communication technology for learning and teaching the English language in Kurdistan of Iraq. English (TESOL) Master Theses. Retrieved from http://scholar.valpo.edu/tesol_matheses/1

Kukulska-Hulme, A. (2012). Language learning defined by time and place: A framework for next generation designs. In J. E. D"1az-Vera (Ed.) Left to my own devices: Learner autonomy and mobile assisted language learning. Innovation and leadership in English language teaching, 6 (pp. 1-13). Emerald Group Publishing.

Lai, K. W., Khaddage, F., \& Knezek, G. (2013). Blending student technology experiences in formal and informal learning. Journal of Computer Assisted Learning, 29(5), 414-425.

Mahajaroenkul, S. (2017). Informal learning strategies of international students seeking to learn English via mass and/or socialmedia. (Unpublished M.A thesis). Wichita State University, KS.

Nguyen, H. \& Terry, D. R. (2017). English learning strategies among EFL learners: A narrative approach. IAFOR Journal of Language Learning, 3(1), 4-19.

Nordin, N., Salehi, H., \& Embi, M. A. (2013). Pros and cons of using ICT in teaching ESL reading and writing. International Education Studies, 6(7), 119-130.

O’Neil, T. \& Snow, P. (2011). Crescent English course for Yemen. Garnet Publishing.

Oxford, R. L. (1990). Language learning strategies: What every teacher should know. Heinle Publishers.

Oxford, R. L. \& Burry-Stock, J. A. (1995). Assessing the use of language learning strategies worldwide with the ESL/EFL version of the strategy inventory for language learning (SILL). System, 23(1), $1-23$.

Pawlak, M. \& Oxford, R. L. (2018). The future of research into language learning strategies. Studies in Second Language Learning and Teaching, 8(2), 525-535.

Pereira, S., Fillol, J., \& Moura, P. (2019). Young people learning from digital media outside of school: The informal meets the formal. Comunicar, 27(58), 41-50.

Sefton-Green, J. (2004). Literature review in informal learning with technology outside school. futurelab series report 7. Retrieved from www.nfer.ac.uk/publications/FUTL72/FUTL72.pdf

Sockett, G. (2013). Understanding the online informal learning of English as a complex dynamic system: An emic approach. ReCALL, 25(1), 48-62.

Stevens, A. (Ed.) (2009). Study on the impact of information and communications technology (ICT) and new media on language learning: Final report no EACEA 2007/09. European Commission, Brussels. Retrieved from http://eacea.ec.europa.eu/LLp/studies/

Trinder, R. (2017). Informal and deliberate learning with new technologies. ELT Journal, 71(4), 401-412.

Valentín, A., Mateos, P. M., González-Tablas, M. M., Pérez, L., López, E., \& García, I. (2013). Motivation and learning strategies in the use of ICTs among university students. Computers \& Education, $61,52-58$.

Vazquez, M. \& Lario-de-Oñate, M.-C. (2009). Language learning strategies and information and communication technology. In A. Klucznik-Töro, A. Csépe, \& D. Kwiatkowska-Ciotucha (Eds), Higher education, partnership, innovation. Publikon Publisher/ID Research Ltd.

Zhou, Y. \& Wei, M. (2018). Strategies in technology-enhanced language learning. Studies in Second Language Learning and Teaching, 8(2), 471-495. 
Social networking

I use social networks (Imo, WhatsApp, Skype, etc.) to talk with English native speakers.

I use social networks (Imo, WhatsApp, etc.) to talk with any fluent speakers of English.

I use social networks (Imo, WhatsApp, etc.) to talk with my colleague in English.

I message my friends via apps.

I chat with native English speakers via social media networks to develop my writing skills.

Accessing Media

I watch English movies to develop my listening skills.

I listen to English songs to develop my pronunciation.

I watch different English movies to train my ears to different English accents and dialects.

I check up the pronunciation of any new word using my mobile electronic dictionary to develop my pronunciation.

I listen to English recordings to develop my vocabulary.

I watch English movies and focus on people's lifestyles.

I watch documentaries to know about the English culture.

I watch grammar lessons daily.

I watch YouTube videos to learn grammar rules.

\section{Accessing Websites}

I read stories online to develop my reading skills.

I read PDF books to develop my reading skills.

I read eBooks to develop my vocabulary.

I use online essay models to develop my essay writing skills.

I use online dictionaries to improve my vocabulary.

I use web-based flashcards to learn vocabulary.

I watch English movies with subtitles to get the meaning of new

vocabulary.

I read eBooks about grammar.

\section{Being Inspired by Someone}

I am a member in many WhatsApp groups and I learn a lot from the members in the group.

I discuss assignments with friends via email discussions.

I got videos from friends by using sharing applications (Bluetooth, Share it, etc.)

I got audios from friends by using sharing applications (Bluetooth, Share it, etc.)

Table A1.

Questionnaire: Mean scores and standard deviations of informal technologybased strategies $(N=100)$ 


\section{LTHE}

17,2

\section{About the authors}

Wagdi Rashad Ali Bin-Hady currently works as an Assistant Professor of Applied Linguistics at Hadhramout University, Faculty of Education Socotra and the Head of the English Department, Yemen. He received PhD degree in English in 2016 from Dr. Babasaheb Ambedkar Marathwada University, India. His research interests include communicative competence, novice teachers, cooperative learning, LLSs in ICT-based environment, flipped learning, task-based and genre-process approaches. Wagdi Rashad Ali Bin-Hady is the corresponding author and can be contacted at: wagdyrashad@gmail.com

Nasser Omer Mubarak Al-Tamimi currently works as a Professor at the English Department, Seiyun University. He received $\mathrm{PhD}$ degree in English Language studies from Universiti Sains Malaysia in 2007. He is interested in linguistics and applied linguistics topics, namely, speaking, writing, metacognitive reading strategies, technology and public speaking.

For instructions on how to order reprints of this article, please visit our website: www.emeraldgrouppublishing.com/licensing/reprints.htm Or contact us for further details: permissions@emeraldinsight.com 